\title{
Geographical disparities of infant mortality in rural China
}

\author{
Yanping Wang, Jun Zhu, Chunhua He, Xiaohong Li, Lei Miao, Juan Liang
}

National Office for Maternal and Child Health Surveillance of China, West China Second University Hospital, Sichuan University, Chengdu, People's Republic of China

\section{Correspondence to}

Dr Juan Liang, National Office for Maternal and Child Health

Surveillance of China, West China Second University Hospital, No 17, Section 3 Ren Min Nan Lu, Chengdu, Sichuan 610041, China; liangjuan002@163.com

Received 27 May 2011 Accepted 8 November 2011 Published Online First 12 January 2012

\author{
ABSTRACT \\ Objective The purpose of the study was to investigate \\ the trends and causes of regional disparities of infant \\ mortality rate (IMR) in rural China from 1996 to 2008. \\ Design A population-based, longitudinal study. \\ Setting The national child mortality surveillance \\ network.
}

Population Population of the 79 surveillance counties. Main outcome measure IMR, leading causes of infant death and the RR of IMR.

Results The IMR in coastal, inland and remote regions declined by $72.4 \%, 62.9 \%$ and $58.2 \%$, respectively, from 1996 to 2008. Compared with the coastal region, the RR of IMR were $1.7(95 \% \mathrm{Cl} 1.6$ to 1.9$), 1.9$ (95\% Cl 1.7 to $2.0)$ and $1.8(95 \% \mathrm{Cl} 1.6$ to 2.0$)$ for inland region and 2.6 (95\% $\mathrm{Cl} 2.4$ to 2.7), 3.2 (95\% $\mathrm{Cl} 3.0$ to 3.5 ) and 3.1 (95\% Cl 2.7 to 3.4) for the remote region during 1996-2000, 2001-2005 and 2006-2008, respectively. The regional disparities existed for both male and female IMRs. The postneonatal mortality showed the highest regional disparities. Pneumonia, birth asphyxia, prematurity/ low birth weight, injuries and diarrhoea were the main contributors to the regional disparities. There were significantly more infants who did not seek healthcare services before death in the remote region relative to the inland and coastal regions.

Conclusion The results indicated persistent existence of regional disparities in IMR in rural China. It is worth noting that regional disparities in IMR increased in the remote and coastal regions during 2001-2005 in rural China. These disparities remained unchanged during 2006-2008. The results indicate that strategies to reduce mortality caused by pneumonia, birth asphyxia and diarrhoea are keys to reducing IMR.

\section{INTRODUCTION}

Over the past two decades, the survival, health and development of children have aroused global concern. Child health disparities have become a considerable problem in global public health. The Millennium Development Goals (MDGs) aim to reduce inequality between countries and within countries. ${ }^{1}$ Reducing infant mortality and narrowing the child health disparity gap are the national goals of many countries, including China. ${ }^{23}$

Infant mortality rate (IMR) is a common indicator for measuring the standard of child health. ${ }^{4}$ Health condition of Chinese children has remarkably improved. Between 1991 and 2008, IMR fell from 51.2 to 14.9 per 1000 live births. ${ }^{5}$ This mortality is lower than a majority of the developing countries. ${ }^{6}$ However, geographical variations in IMR have always been a challenge for Chinese government because of the geographical

\section{What is already known on this subject}

- Infant mortality rate (IMR) is a common indicator of the level of child health.

- The health condition of Chinese children has remarkably improved between 1991 and 2008.

- The regional disparities of IMR were substantial in China between the poorly developed remote rural regions and the well-developed coastal rural regions before 2004.

\section{What this papers adds}

- The regional disparity of IMR increased between the remote and coastal regions in 2001-2005. However, the increasing trend was not observed in 2006-2008.

- Pneumonia, birth asphyxia and diarrhoea were the three main contributors of the regional disparities.

- The healthcare accessibility is significantly lower in the western remote region relative to the other two regions.

divergence and imbalanced economical development. This regional variation is more substantial between the poorly developed remote rural western regions and the well-developed rural coastal regions. ${ }^{7}$ However, there have been no publications regarding the trends and causes of IMR between the two regions in China. There also have been no reports regarding IMR variations in rural China since 2004. In this study, we carried out a nationwide analysis with data from 1996 to 2008 in rural China. The specific aim of this study was to investigate the trends and causes of the geographical disparities of IMR in rural China in order to guide policies aimed at prevention of issues contributing to a high IMR.

\section{METHODS}

\section{Data source}

The data for this study was based on the national children mortality surveillance network. The network monitors a population of 13 million that covers 116 representative districts/counties across 31 provinces using stratified sampling strategies. Details on data collection in the surveillance network have been published previously. ${ }^{8} 9$ Each 


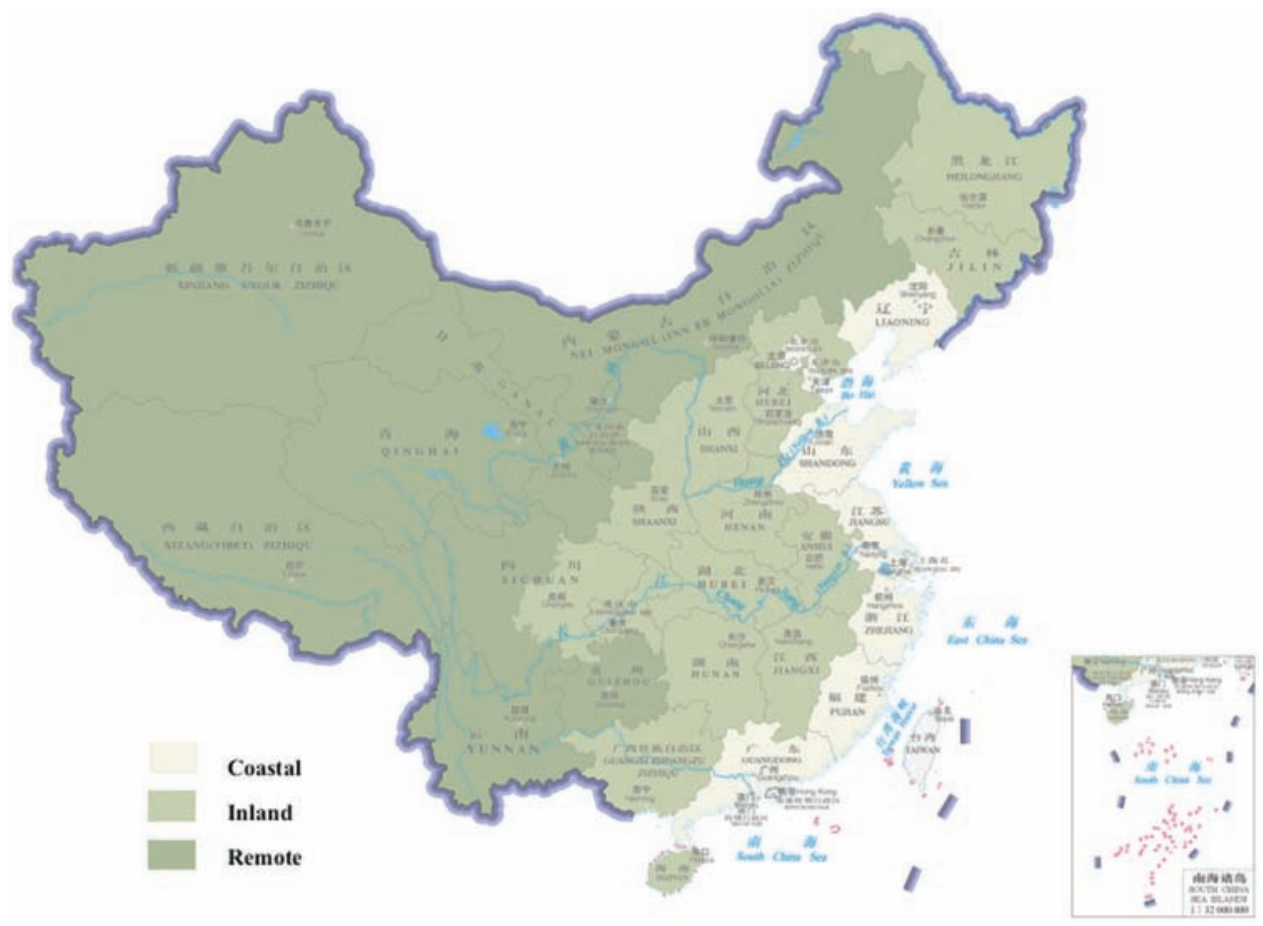

Figure 1 Geographical distribution of coastal, inland and remote regions in China.

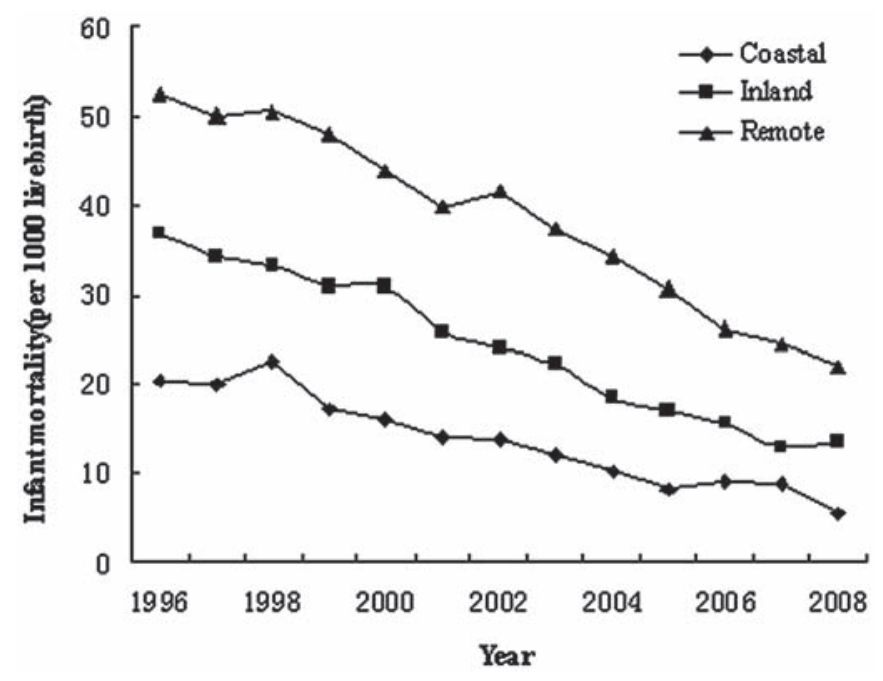

Figure 2 Trend of infant mortality in rural China during 1996-2008.

child death was investigated and reported by doctors and then reviewed by the county-level women and child healthcare institute and the county general hospitals to ensure data accuracy. In addition, quality control of data collection was routinely conducted at all levels of the surveillance network. The causes of death were classified according to the International Classification of Diseases-10 (ICD-10). ${ }^{10}$

\section{Regional categories}

The 31 provinces were divided into coastal, inland and remote regions based on geographical locations and economic conditions. The coastal region includes Beijing, Tianjin, Liaoning, Shanghai, Jiangsu, Zhejiang, Fujian, Shandong and Guangdong. The inland region includes Hebei, Shanxi, Heilongjiang, Jilin,
Anhui, Jiangxi, Henan, Hubei, Hunan, Guangxi, Hainan, Shaanxi, eastern Sichuan and Chongqing. The remote region includes inner Mongolia, Yunnan, Guizhou, Tibet, Gansu, Qinghai, Ningxia, Xinjiang and western Sichuan. Based on the economic conditions, Sichuan Province was divided into eastern Sichuan and western Sichuan which were assigned to the inland and remote region, respectively (figure 1).

Among the 116 representative districts/counties, 79 were in rural areas. Of those in the rural areas, 19 were in the coastal region, 38 in the inland region and 22 in the remote region. All the data used in this study were from the rural regions.

\section{Statistical analysis}

The IMR was calculated as the number of deaths within one year of birth per 1000 live births. IMR was further broken down into early neonate mortality rate (ENMR) (0-6 days of birth), late neonate mortality rate (LNMR) (7-27 days of birth) and post-neonate mortality rate (PNMR) (28-364 days of birth).

Premortality healthcare services were categorised into inpatient, outpatient and untreated groups based on the healthcare encountered $24 \mathrm{~h}$ before death. Healthcare services that the infants received $24 \mathrm{~h}$ before the death were divided into five levels based on the Chinese healthcare system. They are provincial/municipal hospital, county/district hospital, township/neighbourhood hospital, village doctor and no healthcare seeking. For this study, the hospital at the highest level was recorded as the level of hospital visited before death if two or more hospitals had been visited. Accessibility to healthcare was indicated by premortality treatment, the proportion of each category of hospitals visited and the proportion of infants not seeking healthcare. Injury-related death is not included due to the low hospital visiting rate after incidence of injury.

We artificially assigned the whole observational period from 1996 to 2008 into three periods (1996-2000, 2001-2005 and 2006-2008) for statistical purposes because the annual number of deaths was too low to precisely calculate the mortality. 
Table 1 IMR in different regions in rural China

\begin{tabular}{|c|c|c|c|c|c|c|c|c|c|c|c|c|}
\hline \multirow[b]{2}{*}{ Location } & \multicolumn{4}{|c|}{$1996-2000$} & \multicolumn{4}{|c|}{ 2001-2005 } & \multicolumn{4}{|c|}{ 2006-2008 } \\
\hline & Live births & Death & Mortality* & RR $(95 \% \mathrm{CI})$ & Live births & Death & Mortality* & RR (95\% CI) & Live births & Death & Mortality* & $\mathbf{R R}(95 \% \mathrm{CI})$ \\
\hline \multicolumn{13}{|c|}{ Early neonatal } \\
\hline Coastal & 56538 & 656 & 11.6 & 1 & 62742 & 419 & 6.7 & 1 & 47940 & 204 & 4.3 & 1 \\
\hline Inland & 95874 & 1943 & 20.3 & 1.7 (1.6 to 1.9$)$ & 105842 & 1363 & 12.9 & 1.9 (1.7 to 2.2$)$ & 82837 & 698 & 8.4 & 2.0 (1.7 to 2.3$)$ \\
\hline Remote & 78995 & 1830 & 23.2 & 2.0 (1.8 to 2.2$)$ & 70341 & 1308 & 18.6 & $2.8(2.5$ to 3.1$)$ & 46987 & 549 & 11.7 & 2.7 (2.3 to 3.2$)$ \\
\hline \multicolumn{13}{|c|}{ Late neonatal } \\
\hline Coastal & 56538 & 173 & 3.1 & 1 & 62742 & 98 & 1.6 & 1 & 47940 & 53 & 1.1 & 1 \\
\hline Inland & 95874 & 463 & 4.8 & $1.6(1.3$ to 1.9$)$ & 105842 & 331 & 3.1 & 2.0 (1.6 to 2.5$)$ & 82837 & 145 & 1.8 & 1.6 (1.2 to 2.2$)$ \\
\hline Remote & 78995 & 588 & 7.4 & 2.4 (2.1 to 2.9$)$ & 70341 & 400 & 5.7 & 3.6 (2.9 to 4.5$)$ & 46987 & 184 & 3.9 & 3.5 (2.6 to 4.8$)$ \\
\hline \multicolumn{13}{|c|}{ Postneonatal } \\
\hline Coastal & 56538 & 256 & 4.5 & 1 & 62742 & 194 & 3.1 & 1 & 47940 & 118 & 2.5 & 1 \\
\hline Inland & 95874 & 787 & 8.2 & 1.8 (1.6 to 2.1$)$ & 105842 & 549 & 5.2 & $1.7(1.4$ to 2.0$)$ & 82837 & 319 & 3.9 & $1.6(1.3$ to 1.9$)$ \\
\hline Remote & 78995 & 1452 & 18.4 & 4.1 (3.6 to 4.6$)$ & 70341 & 869 & 12.4 & 4.0 (3.4 to 4.7$)$ & 46987 & 393 & 8.4 & $3.4(2.8$ to 4.2$)$ \\
\hline \multicolumn{13}{|l|}{ Infant } \\
\hline Coastal & 56538 & 1085 & 19.2 & 1 & 62742 & 711 & 11.3 & 1 & 47940 & 375 & 7.8 & 1 \\
\hline Inland & 95874 & 3193 & 33.3 & $1.7(1.6$ to 1.9$)$ & 105842 & 2243 & 21.2 & $1.9(1.7$ to 2.0$)$ & 82837 & 1162 & 14.0 & $1.8(1.6$ to 2.0$)$ \\
\hline Remote & 78995 & 3870 & 49.0 & $2.6(2.4$ to 2.7$)$ & 70341 & 2577 & 36.6 & $3.2(3.0$ to 3.5$)$ & 46987 & 1126 & 24.0 & 3.1 (2.7 to 3.4$)$ \\
\hline
\end{tabular}

*Mortality was calculated as the number of the deaths per 1000 live births.

Table 2 IMR in different genders in rural China

\begin{tabular}{|c|c|c|c|c|c|c|c|c|c|c|c|c|c|c|c|}
\hline \multirow[b]{2}{*}{ Sex } & \multicolumn{5}{|c|}{$1996-2000$} & \multicolumn{5}{|c|}{ 2001-2005 } & \multicolumn{5}{|c|}{$2006-2008$} \\
\hline & $\begin{array}{l}\text { Live } \\
\text { births }\end{array}$ & $\begin{array}{l}\text { Infant } \\
\text { death }\end{array}$ & IMR* & $\begin{array}{l}\mathrm{RR}+(95 \% \mathrm{CI}) \\
\text { male: female }\end{array}$ & $\begin{array}{l}\text { RR‡ } \\
(95 \% \mathrm{CI})\end{array}$ & $\begin{array}{l}\text { Live } \\
\text { births }\end{array}$ & $\begin{array}{l}\text { Infant } \\
\text { death }\end{array}$ & IMR* & $\begin{array}{l}\text { RRt }(95 \% \mathrm{CI}) \\
\text { male: female }\end{array}$ & $\begin{array}{l}\text { RR } \\
(95 \% \text { CI) }\end{array}$ & $\begin{array}{l}\text { Live } \\
\text { births }\end{array}$ & $\begin{array}{l}\text { Infant } \\
\text { death }\end{array}$ & IMR* & $\begin{array}{l}\text { RRt (95\% CI) } \\
\text { male: female }\end{array}$ & $\begin{array}{l}\text { RR } ¥ \\
(95 \% \mathrm{CI})\end{array}$ \\
\hline \multicolumn{16}{|l|}{ Female } \\
\hline Coastal & 26271 & 457 & 17.4 & 1 & 1 & 28865 & 350 & 12.1 & 1 & 1 & 22144 & 165 & 7.5 & 1 & 1 \\
\hline Inland & 44770 & 1530 & 34.2 & 1 & $\begin{array}{l}2.0 \\
(1.8 \text { to } 2.2)\end{array}$ & 48065 & 1023 & 21.3 & 1 & $\begin{array}{l}1.8 \\
(1.6 \text { to } 2.0)\end{array}$ & 37938 & 488 & 12.9 & 1 & $\begin{array}{l}1.7 \\
\text { (1.4 to } 2.1 \text { ) }\end{array}$ \\
\hline Remote & 37778 & 1815 & 48.0 & 1 & $\begin{array}{l}2.8 \\
(2.5 \text { to } 3.1)\end{array}$ & 33064 & 1166 & 35.3 & 1 & $\begin{array}{l}2.9 \\
(2.6 \text { to } 3.3)\end{array}$ & 22018 & 525 & 23.8 & 1 & $\begin{array}{l}3.2 \\
\text { (2.7 to } 3.8 \text { ) }\end{array}$ \\
\hline \multicolumn{16}{|l|}{ Male } \\
\hline Coastal & 30265 & 627 & 20.7 & $\begin{array}{l}1.2 \\
\text { (1.1 to } 1.3)\end{array}$ & 1 & 33875 & 360 & 10.6 & $\begin{array}{l}0.9 \\
(0.8 \text { to } 1.0)\end{array}$ & 1 & 25796 & 210 & 8.1 & $\begin{array}{l}1.1 \\
(0.9 \text { to } 1.3)\end{array}$ & 1 \\
\hline Inland & 51101 & 1663 & 32.5 & $\begin{array}{l}1.0 \\
(0.9 \text { to } 1.0)\end{array}$ & $\begin{array}{l}1.6 \\
(1.4 \text { to } 1.7)\end{array}$ & 57775 & 1218 & 21.1 & $\begin{array}{l}1.0 \\
(0.9 \text { to } 1.1)\end{array}$ & $2.0(1.8$ to 2.2$)$ & 44892 & 670 & 14.9 & $\begin{array}{l}1.2 \\
(1.0 \text { to } 1.3)\end{array}$ & $\begin{array}{l}1.8 \\
\text { (1.6 to } 2.1 \text { ) }\end{array}$ \\
\hline Remote & 41210 & 2050 & 49.7 & $\begin{array}{l}1.0 \\
(1.0 \text { to } 1.1)\end{array}$ & $\begin{array}{l}2.4 \\
(2.2 \text { to } 2.6)\end{array}$ & 37273 & 1411 & 37.9 & $\begin{array}{l}1.1 \\
\text { (1.0 to } 1.2 \text { ) }\end{array}$ & $\begin{array}{l}3.6 \\
(3.2 \text { to } 4.0)\end{array}$ & 24965 & 600 & 24.0 & $\begin{array}{l}1.0 \\
(0.9 \text { to } 1.1)\end{array}$ & $\begin{array}{l}3.0 \\
(2.5 \text { to } 3.5)\end{array}$ \\
\hline
\end{tabular}

Thirty-three live births and 14 infant deaths were excluded due to the missed gender information.

*IMR was calculated as the number of infant deaths $(<1$ year) per 1000 live births.

tRR of male IMR relative to the female IMR within the same region.

$\ddagger R R$ of IMR in the remote or inland region relative to the IMR of the same gender in coastal region.

IMR, infant mortality.

SAS 9.0 (SAS Institute, Carey, North Carolina, USA) was used for the data statistical analysis. Cases that had missing information in the categories analysed were excluded for statistical analysis, but were included in other categories that had complete information. The Cochran-Armitage test was conducted to calculate the IMR and the causes-specific IMR over time within each region. The Woolf method was used to calculate the RR and 95\% CI between different regions. Consistency for RR of the mortality or cause-specific IMR between regions during the three time periods was tested by Woolf's Consistency Test. If the RR were inconsistent between different periods, the interaction exists between region and time periods. ${ }^{11} 12$

\section{RESULTS}

From 1996 to 2008, the reduction of IMR in the coastal, inland and remote regions were $72.4 \%, 62.9 \%$ and $58.2 \%$, respectively $(\mathrm{p}<0.01)$, with a significantly less decline in the remote region (figure 2). The ENMR was the highest, followed by PNMR and then LNMR. Compared with the coastal region, the RR of ENMR, LNMR and IMR increased from 2.0 (95\% CI 1.8 to 2.2), 2.4 (95\% CI 2.1 to 2.9 ) and 2.6 (95\% CI 2.4 to 2.7 ), respectively, during $1996-2000$ to 2.8 (95\% CI 2.5 to 3.1$), 3.6(95 \%$ CI 2.9 to 4.5 ) and 3.2 (95\% CI 3.0 to 3.5 ) during 2001-2005 in the remote region $(p<0.01)$. These rates stayed flat during the 2006-2008. The RR of the abovementioned mortalities were not changed when comparing the inland region with the coastal region during 1996-2008 ( $\mathrm{p}>0.05$ ) (table 1).

As of the gender impact on IMR, first we examined the regional difference in each gender. Both genders had higher IMRs in the inland and remote regions than in the coastal region. Then next, we examined the IMR difference between the two genders. The RRs presented here were the IMR of male infants relative to the female infants. The RRs were greater 
Table 3 Risks of cause-specific infant mortality in the three regions in rural China

\begin{tabular}{|c|c|c|c|c|c|c|}
\hline \multirow[b]{2}{*}{ Cause of dewath } & \multicolumn{3}{|c|}{ Cause-specific mortality (per 100000 live births) } & \multicolumn{3}{|c|}{$\mathbf{R R}(95 \% \mathrm{CI})$} \\
\hline & Coastal & Inland & Remote & Coastal & Inland & Remote \\
\hline \multicolumn{7}{|l|}{ Pneumonia } \\
\hline $1996-2000$ & 334.3 & 751.0 & 1383.6 & 1 & $2.2(1.9$ to 2.6$)$ & $4.1(3.5$ to 4.8$)$ \\
\hline $2001-2005$ & 116.3 & 343.9 & 922.6 & 1 & $3.0(2.3$ to 3.8$)$ & $7.9(6.2$ to 10.1$)$ \\
\hline $2006-2008$ & $91.8^{*}$ & $201.6^{*}$ & $487.4^{*}$ & 1 & 2.2 (1.6 to 3.1$)$ & 5.3 (3.8 to 7.3 ) \\
\hline \multicolumn{7}{|l|}{ Birth asphyxia } \\
\hline 1996-2000 & 332.5 & 708.2 & 839.3 & 1 & 2.1 (1.8 to 2.5$)$ & $2.5(2.1$ to 3.0$)$ \\
\hline 2001-2005 & 188.1 & 421.4 & 706.6 & 1 & 2.2 (1.8 to 2.7$)$ & 3.8 (3.1 to 4.6$)$ \\
\hline 2006-2008 & $96.0^{*}$ & $255.9^{*}$ & $468.2^{*}$ & 1 & 2.7 (1.9 to 3.7$)$ & 4.9 (3.6 to 6.7$)$ \\
\hline \multicolumn{7}{|l|}{ Prematurity/LBW } \\
\hline 1996-2000 & 429.8 & 618.5 & 751.9 & 1 & 1.4 (1.2 to 1.7$)$ & 1.7 (1.5 to 2.0$)$ \\
\hline $2001-2005$ & 302.8 & 440.3 & 673.9 & 1 & $1.5(1.2$ to 1.7$)$ & $2.2(1.9$ to 2.6$)$ \\
\hline 2006-2008 & $198.2^{*}$ & $300.6^{*}$ & $470.3^{*}$ & 1 & 1.5 (1.2 to 1.9$)$ & $2.4(1.9$ to 3.0$)$ \\
\hline \multicolumn{7}{|l|}{ Injuries } \\
\hline 1996-2000 & 122.0 & 328.6 & 415.2 & 1 & 2.7 (2.1 to 3.5$)$ & 3.4 (2.6 to 4.4$)$ \\
\hline 2001-2005 & 84.5 & 196.5 & 209.0 & 1 & $2.3(1.7$ to 3.1$)$ & 2.5 (1.8 to 3.4$)$ \\
\hline 2006-2008 & $68.8^{*}$ & $134.0^{*}$ & $146.8^{*}$ & 1 & 1.9 (1.3 to 2.9$)$ & 2.1 (1.4 to 3.2$)$ \\
\hline \multicolumn{7}{|l|}{ Diarrhoea } \\
\hline 1996-2000 & 46.0 & 88.7 & 358.3 & 1 & $1.9(1.2$ to 3.0$)$ & 7.8 (5.2- to 11.6$)$ \\
\hline 2001-2005 & 9.6 & 57.6 & 231.7 & 1 & $6.0(2.6$ to 13.9$)$ & $24.2(10.7$ to 54.7$)$ \\
\hline 2006-2008 & 14.6 & $32.6^{*}$ & $159.6^{*}$ & 1 & $2.2(1.0$ to 5.1$)$ & 10.9 (5.0 to 23.7$)$ \\
\hline \multicolumn{7}{|c|}{ Congenital anomalies } \\
\hline $1996-2000$ & 392.7 & 354.6 & 308.9 & 1 & $0.9(0.8$ to 1.1$)$ & $0.8(0.7$ to 0.9$)$ \\
\hline $2001-2005$ & 293.3 & 327.8 & 321.3 & 1 & 1.1 (0.9 to 1.3$)$ & 1.1 (0.9 to 1.3$)$ \\
\hline 2006-2008 & $219.0^{*}$ & $294.6^{*}$ & 278.8 & 1 & $1.3(1.1$ to 1.7$)$ & $1.3(1.0$ to 1.6$)$ \\
\hline
\end{tabular}

${ }^{*} \mathrm{p}<0.05$ time trend from 1996-2000 to 2006-2008.

LBW, low birth weight.

than 1 during periods 1996-2000 and 2006-2008, with the exception of period 2001-2005. The $95 \%$ CI of RR were 0.9 to $1.3,1.0$ to 1.3 and 0.9 to 1.1 during $2006-2008$ in the coastal, inland and remote regions, respectively (table 2 ).

The main diseases that caused infant deaths were pneumonia, birth asphyxia, prematurity/low birth weight (LBW), diarrhoea, injuries and congenital anomalies, which accounted for $80 \%$ of the total infant deaths. Most of the cause-specific mortalities declined within each region $(p<0.01)$ with the exception that there were no significant changes for diarrhoeacaused IMR in the coastal region and congenital anomalycaused IMR in the remote region (table 3 ).

Compared with the coastal region, the inland and remote regions had higher IMRs resulted from pneumonia, birth asphyxia, prematurity/LBW, injuries and diarrhoea during the entire study time period with the exception of the diarrhoeacaused IMR in inland region during 2006-2008. Compared with the coastal region, the RR of IMRs caused by pneumonia, birth asphyxia, prematurity/LBW, diarrhoea and congenital anomalies increased during 2001-2005 for the remote regions $(p<0.05)$. There was no significant change during 2006-2008. The RR of the abovementioned cause-specific IMR, except congenital anomalies between inland and coastal region, had no significant change during the three time periods $(p>0.05)$ (table 3).

A high accessibility was considered when the infants visited the provincial/municipal or county/district hospitals before death. Individuals seeking treatment at hospitals in these two levels significantly increased throughout all three regions. However, during 2006-2008, the percentage of individuals going to higher-levelled hospitals was significantly lower in the remote region (56\%) relative to the coastal region (84\%) (table 4).
There was a steady increase in inpatient care throughout the three regions. A persistent decrease of infants who did not seek healthcare service was also seen, with the greater proportion of infants who did not visit doctors in the remote region $(25 \%)$ relative to the coastal region $(5 \%)(p<0.01)$ (table 4$)$.

Reasons behind the lack of healthcare-seeking behaviour before infant death were explored. We analysed data from 2003 to 2008 because the network only collected information regarding this matter during this time period. The time period was divided into 2003-2005 and 2006-2008 for statistical purposes. In the coastal region, the main reasons for no healthcare seeking were delayed hospital visits and others (parents gave up treatment due to severe congenital anomalies of infants) during these two time periods. For the inland and remote region, the main reasons included delayed hospital visits, lack of knowledge of the severity of the diseases among the parents, religious or ethnic beliefs and financial difficulties. In the remote region, the cases of infant death due to the parent's lack of knowledge were significantly higher during 2006-2008 than 2003-2005. Other main reasons also included financial difficulties (11\%) and transportation issues (9\%) in the remote region (figure 3). There were some missing data in this study. But the bias can be ignored since only less than $0.5 \%$ data were missing.

\section{DISCUSSION}

In rural China, the regional disparities of ENMR, LNMR, PNMR and IMR are still an issue although IMRs are remarkably declined. Disparities in PNMR were higher than ENMR and LNMR. Regional disparities in IMR exist in both genders. Between the remote and the coastal regions, disparities in IMR were significantly higher during 2001-2005 and remained flat during 2006-2008. Liu et al reported that the IMR was 
Table 4 Proportion of premortality treatment and premortality healthcare service among the three regions in rural China

\begin{tabular}{|c|c|c|c|c|c|c|c|c|c|}
\hline & \multicolumn{3}{|c|}{ 1996-2000 } & \multicolumn{3}{|c|}{ 2001-2005 } & \multicolumn{3}{|c|}{$2006-2008$} \\
\hline & Coastal (\%) & Inland (\%) & Remote (\%) & Coastal (\%) & Inland (\%) & Remote (\%) & Coastal (\%) & Inland (\%) & Remote (\%) \\
\hline \multicolumn{10}{|l|}{ Premortality treatment } \\
\hline Inpatient treatment & 71 & 38 & 27 & 78 & 57 & 39 & 83 & 74 & 55 \\
\hline Outpatient treatment & 23 & 47 & 33 & 16 & 29 & 29 & 12 & 16 & 20 \\
\hline No healthcare seeking & 6 & 15 & 40 & 6 & 14 & 32 & 5 & 10 & 25 \\
\hline \multicolumn{10}{|l|}{ Premortality healthcare service } \\
\hline Provincial/municipal hospital & 18 & 5 & 7 & 31 & 11 & 11 & 32 & 21 & 24 \\
\hline County/district hospital & 41 & 28 & 19 & 44 & 43 & 26 & 52 & 52 & 32 \\
\hline Township/neighbourhood hospital & 25 & 22 & 13 & 17 & 19 & 15 & 14 & 16 & 12 \\
\hline Village doctor & 13 & 36 & 29 & 6 & 18 & 23 & 1 & 6 & 12 \\
\hline No healthcare service seeking & 3 & 9 & 32 & 2 & 9 & 25 & 1 & 5 & 20 \\
\hline
\end{tabular}

Twenty-eight infant deaths were excluded due to the 'missed information for premortality treatment or premortality healthcare service.

$\square$ others

$\square$ religious or ethic beliefs

lack of knowledge of the severity of the diseases

$\square$ delayed hospit al visits

$\square$ transportation issues

$\square$ financial difficulties

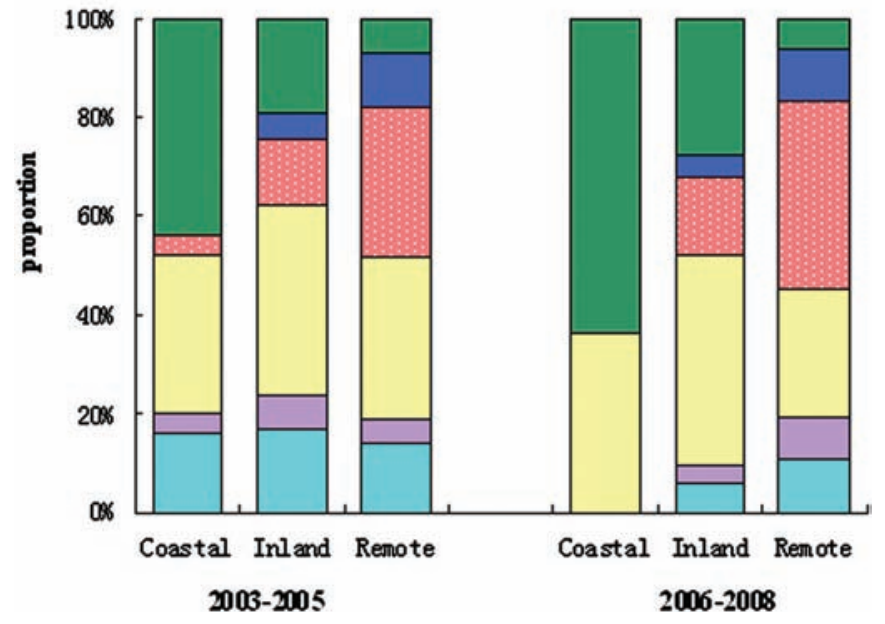

Figure 3 The proportion of reasons behind the lack of healthcareseeking behaviour before infant death in the three regions during the period of 2003-2005 and 2006-2008.

significantly higher in six provinces in the western region relative to the four provinces in the coastal region and two inland provinces from 1990 to $2000 .^{7}$ Our results showed a similar trend, but on a much larger scale and over a longer time period. Furthermore, it has been demonstrated that the regional disparities in IMR in China are not improved. Disparities in children's health have not been significantly reduced in developed or underdeveloped countries. The disparities in children's health challenge the Chinese government and a majority of the countries globally. ${ }^{13-19}$

Our findings showed that more than $60 \%$ of infant deaths happened during the neonatal period and more than $75 \%$ of neonatal deaths happened during the early neonatal period. Our results are similar to reports published by a number of other countries. ${ }^{20}$ Tomashek et al reported that the neonatal mortality rate (NMR) among American Caucasian was counted for $62.0 \%$ of the IMR. ${ }^{21}$ During the past two decades, the NMR has been declining very slowly in a majority of countries. To achieve the MDGs and reduce the mortality of children and infants, the United Nations' Children's Fund stresses strategies that efficiently reduce NMRs. ${ }^{22}$ Our results indicate that the PNMR had the highest regional disparities. This is similar to what the reports by Bladwin showed that the adjusted OR for PNMR between American Indians and Alaska natives and rural Whites was higher than that for NMR between them (1.46 vs 0.85$).{ }^{23}$

During 2006 to 2008, the $95 \%$ CI of RR of male IMR versus female IMR in the coastal and inland regions were 0.9 to 1.3 and 1.0 to 1.3 , respectively. Considering that the range of this RR between 1.2 and 1.3 was commonly accepted as a standard by a number of studies, ${ }^{24}$ our data suggested that there was no significant IMR difference between genders in the coastal and inland regions. The remote region had relative higher IMR in female than male infants, which was similar to the reports from east Asia and South Asia. ${ }^{25}$

The reason of variations in IMR, although not clear, may be complex and synergistic. It can be attributed to multiple factors such as socioeconomic circumstances, healthcare accessibility and fertility rate. ${ }^{26-30}$ The socioeconomic factor is probably one of the major contributors to the inequality in infant mortality in rural China. First, although the Chinese economy has been rapidly growing in the past 10 years, the gap of gross domestic product per person between the coastal and remote western regions in 2008 was increasing when compared with $2000 .^{31}$ The imbalanced rapid economy growth may have contributed to the unchanged RR of IMR between 2001-2005 and 2006-2008 for the remote region relative to the coastal region. Secondly, among the 592 poorest counties, 366 were in the remote regions where $66 \%$ of the population was in poverty. ${ }^{32}$ Third, $10.7 \%$ of the infant death in the untreated group in the remote region in our study was due to financial difficulties.

Our results indicated that lack of accessibility to health services and lack of knowledge of care-seeking/warning signs among parents may be the main impact to the regional disparities of IMR. Healthcare accessibility is negatively correlated with infant mortality (Shi et al). ${ }^{27}$ Limited healthcare resources could be one of the major contributors to the limited accessibility of healthcare. A national healthcare survey in 2008 showed that the number of healthcare workers in township hospitals and village clinics was 1.37 and 1.22 per 1000 rural populations in the coastal region, while 0.95 and 0.91 in the remote region, respectively. ${ }^{33}$ In this study, the significantly lower number of visits to provincial/municipal and county/district hospital before infant death in the remote region relative to the other two regions further supports the importance of the healthcare accessibility. The analysis on the reasons for dead infants without treatment before death during 2006-2008 indicated that $39 \%$ were caused by unawareness of the severity of the disease among parents and $26 \%$ by delayed hospital 
visiting. Both of the two main reasons may suggest a relative lower education level of the parents.

IMR is positively correlated with total fertility rate. ${ }^{21}$ The total fertility rate dropped from 2.9 in 1979, when the onechild policy started, to 1.7 in $2004 . .^{34} 35$ The one-child policy actually allows two children per family if you are a minority. These individuals mostly live in the remote region of China (73.15\% in 1990). The average fertility rate is $2.0-2.5$ in the remote region, while the rate is more than 3.0 for over $50 \%$ of the minorities. ${ }^{36-38}$ This indirectly supported the relationship of fertility rate to IMR.

Pneumonia, birth asphyxia, prematurity/LBW, injuries and diarrhoea were the main diseases that caused an increased $R R$ in IMR in the remote region compared with the coastal region. This indicates that certain procedures are able to facilitate the improvement of regional disparities in infant mortality such as resuscitation training to decrease birth-asphyxia-related mortality. ${ }^{39} 40$

The limitations of our study included the following: (1) we did not have data related to household income and maternal education and age, which prevented us from researching the direct relationship between these factors and IMR. (2) We did not have data of healthcare service for the whole population. Our analysis was based on the healthcare provided to the infants before death. Therefore, our results about the healthcare accessibility were biased.

To summarise, this study indicated remarkable declines in IMR in rural China in the past 13 years with the preservation of regional variations. It is worth noting that regional disparities in IMR increased between the remote and coastal regions in 2001-2005. However, the increasing trend was not observed in 2006-2008. Pneumonia, birth asphyxia and diarrhoea were the three main contributors to the regional disparities. This data may provide a basic information and may help direct Chinese government to reduce the geographical disparities by increasing healthcare accessibility, by formulating related policies and by enhancing doctor training on neonate resuscitation.

Acknowledgements The authors would like to thank all health workers in this surveillance system for providing the data and investigating the cause of death.

Funding This work was supported by the Ministry of Health, China (grants OT2003009 and 05 wsb-02) and UNICEF (grant YH601-11-1141) and Program for Changjiang Scholars and Innovative Research Team in University (IRT0935).

Competing interests None.

Provenance and peer review Not commissioned; externally peer reviewed.

\section{REFERENCES}

1. World Health Organization. The world health report 2000; health systems: improving performance. Geneva: WHO, 2000.

2. Evans T, Whitehead M, Diderichsen $\mathrm{F}$, et al. Challenging Inequities in Health: From Ethics to Action. Oxford: Oxford University Press 2001.

3. National Working Committee for Children and Women under the State Council. National Program of Action for Child Development in China (2001-2010) http:// www.nwccw.gov.cn/html/49/n-140649.html (accessed Feburary 2011).

4. Reidpath DD, Allotey P. Infant mortality rate as an indicator of population health J Epidemiol Community Health 2003;57:344-6.

5. Ministry of Health of China. Mortality Rate of Children Under 5-year in Surveillance Region(In Chinese). http: //www.moh.gov.cn/publicfiles/business/ htmlfiles/zwgkzt/ptjty/digest2009/T3/sheet004.htm (accessed October 2010).

6. United Nations Children's Fund. The State of the World's Children 2009. New York: UNICEF 2008

7. Liu B, Jiang F, Hu SL. Geographic differences on population's health. Chinese Health Resources 2006:9:12-14.

8. Wang YP, Miao L, Qian YQ, et al. Analysis of under 5 years old children mortality and the leading death cause in China from 1996 to 2000. Chin J Prev Med 2005:39:260-4.
9. Wang YP, Miao L, Dai L, et al. Mortality rate for children under 5 years of age in China from 1996 to 2006. Public Health 2011;125:301-7.

10. World Health Organization. International Statistical Classification of Diseases and Related Health Problem (ICD-10). 10th rev. Geneva: WHO 1993

11. Ruan RS. Epidemiology Principles and Methods. First edition. Chengdu: Sichuan University Press 2004.

12. Jia ZO. The methods of interaction analysis. In: Zhao ZZ, ed. Epidemiological research method and application. Second edition. Beijing: Science press 2005;523-44.

13. Laskar MS, Harada N. Trends and regional variations in infant mortality rates in Japan, 1973-1998. Public Health 2005:119:659-63.

14. World Health Organization. The World Health Report 2008 - Primary Health Care (now more than ever). Geneva: WHO, 2008

15. Alexander GR, Wingate MS, Bader D, et al. The increasing racial disparity in infant mortality rates: composition and contributors to recent US trends. Am J Obstet Gynecol 2008;198:51.e1-9.

16. Matijasevich A, Victora CG, Barros AJ, et al. Widening ethnic disparities in infant mortality in southern Brazil: comparison of 3 birth cohorts. Am J Public Health 2008;98:692-68.

17. Movahedi M, Hajarizadeh B, Rahimi A, et al. Trends and geographical inequalities of the main health indicators for rural Iran. Health Policy Plan 2009;24:229-37.

18. Gonzalez R, Requejo JH, Nien JK, et al. Tackling health inequities in Chile: maternal, newborn, infant, and child mortality between 1990 and 2004. Am J Public Health 2009:99:1220-6.

19. World Health Organization. World Health Statistics 2006. Available at: http:// www.who.int/whosis/whostat2006 erratareduce.pdf (accessed Oct ober 2010).

20. Lawn JE, Cousens S, Zupan J. 4 million neonatal deaths: When? Where? Why? Lancet 2005; 365:891-900.

21. Tomashek KM, Oin C, Hsia J, et al. Infant mortality trends and differences between American Indian/Alaska Native infants and white infants in the United States, 1989-1991 and 1998-2000. Am J Public Health 2006;96:2222-7.

22. UNICEF. The State of the World's Children 2008. New York:UNICEF 2005.

23. Baldwin LM, Grossman DC, Murowchick E, et al. Trends in perinatal and infant health disparities between rural American Indians and Alaska natives and rural Whites. Am J Public Health 2009;99:638-46.

24. Khanna R, Kumar A, Vaghela JF, et al. Community based retrospective study of sex in infant mortality in India. BMJ 2003;327:126.

25. Han SH, Li SZ. China's mode of child deaths and changes in gender. Chinese Journal of Public Health 1999;15:930-1.

26. Son M, Oh J, Choi YJ, et al.(The effects of the parents' social class on infant and child death among 1995-2004 birth cohort in Korea). J Prev Med Public Health 2006;39:469-76

27. Shi L, Macinko J, Starfield B, et al. Primary care, infant mortality, and low birth weight in the states of the USA. J Epidemiol Community Health 2004; 58:374-80.

28. Peña $\mathbf{R}$, Wall S, Persson LA. The effect of poverty, social inequity, and maternal education on infant mortality in Nicaragua, 1988-1993. Am J Public Health 2000:90:64-9.

29. Jahan S. Poverty and infant mortality in the Eastern Mediterranean region: a meta-analysis. J Epidemiol Community Health 2008:62:745-51.

30. Feachem RG. Poverty and inequity: a proper focus for the new century. Bull World Health Organ 2000;78:1-2.

31. National Bureau of Statistics of China. China Statistical Yearbook 2008. Beijing: National Bureau of Statistics of China, 2009

32. The State Council Leading Group Office of Poverty Alleviation and Development. The list of state-level poverty-stricken counties in 1987. http://www.cpad.gov.cn/ data/2006/0303/article 311.htm (accessed April 2011).

33. Center for Health Statistics and information, MOH. Research on health services of primary health care facilities in China, 2008. Beijing: Peking Union Medical College Press, 2009

34. Hesketh T, Lu L, Xing ZW. The effect of China's one-child family policy after 25 years. N Engl J Med 2005;353:1171-6.

35. Zhai ZW, Chen W. Chinese Fertility in the 1990s. Population Research 2007;31:19-32.

36. National Bureau of Statistics of China. Geographic Distribution of Ethnic Minorities. http://www.stats.gov.cn/tjsj/ndsj/2009/html/B0111e.htm (accessed Feburary 2011)

37. Yuan X. Population transition and its further development in the West of China Market \& Demographic Analysis 2000;6:19-23.

38. Huang RO. Minority Population and Development in the West of China. Population \& Economics 2001;129:3-8.

39. Hogue CJ, Vasquez C. Toward a strategic approach for reducing disparities in infant mortality. Am J Public Health 2002;92:552-6.

40. Gonzalez $\mathbf{R}$, Merialdi $\mathrm{M}$, Lincetto 0 , et al. Reduction in neonatal mortality in Chile between 1990 and 2000. Pediatrics 2006;117:e949-54. 